\title{
REAC regenerative treatment efficacy in experimental chondral lesions: a pilot study on ovine animal model
}

This article was published in the following Dove Press journal:

Clinical Interventions in Aging

14 September 2017

Number of times this article has been viewed

\author{
Eraldo Sanna Passino $0^{1,2}$ \\ Stefano Rocca' \\ Sabrina Caggiu' \\ Nicolò Columbano ${ }^{1,2}$ \\ Alessandro Castagna ${ }^{3}$ \\ Vania Fontani ${ }^{3-5}$ \\ Salvatore Rinaldi ${ }^{3-5}$ \\ 'Department of Veterinary Medicine, \\ University of Sassari, Sassari, Italy; \\ ${ }^{2}$ Comparative Surgery Research \\ Laboratory, University of Sassari, \\ Sassari, Italy; ${ }^{3}$ Department of \\ Regenerative Medicine, Rinaldi \\ Fontani Institute, Florence, Italy; \\ ${ }^{4}$ Research Department, Rinaldi \\ Fontani Foundation, Florence, Italy; \\ ${ }^{5}$ Research Department, IRF Shanghai \\ Biomedical Sciences, Shanghai, \\ People's Republic of China
}

\begin{abstract}
Radioelectric asymmetric conveyor (REAC) technology is a platform designed to optimize cell polarity. Cell polarity is a universal biological phenomenon that is implicated in cell differentiation, proliferation, morphogenesis, aging, and rejuvenation. In this work, we investigate a timing and administration protocol for tissue optimization regenerative treatment type $\mathrm{C}$, in order to treat aging-related chondral damage or injuries and gain insights into regenerative processes of articular cartilage in humans. The chondral lesion produced in this study in an animal model ( 6 knee joints of 4 adult sheep) was $6 \mathrm{~mm}$ in diameter and about $2 \mathrm{~mm}$ deep. These lesions, which did not involve subchondral bone, tend to increase in size and depth and are not completely repaired with normal hyaline articular cartilage since adult articular cartilage is avascular and has a very slow turnover at the cellular and molecular level. Moreover, the hydration of articular cartilage is reduced with aging and with decreased mitotic activity, synthesis, and population size of chondrocytes. Six months posttreatment, lesions appeared filled, though not completely, with newly generated tissue of the light opalescent color of healthy articular cartilage, which otherwise covered the underlying subchondral bone. The newly formed tissue surface appeared to be quite regular. Nearly complete regeneration of subchondral bone occurred, with little vascularization and ossification nuclei almost absent. The results of this study confirm previous data obtained in vitro on the regenerative effects of REAC technology on human normal and osteoarthritic chondrocytes exposed to IL-1 $\beta$. The present findings indicate that REAC tissue optimization-regenerative treatment type $\mathrm{C}$ is a promising therapeutic tool among the other REAC regenerative treatment protocols for the treatment of cartilage lesions.
\end{abstract}

Keywords: aging, senescence, articular cartilage, regenerative medicine, regenerative physical treatments, radio electric asymmetric conveyer

\section{Introduction}

Radioelectric asymmetric conveyor (REAC) technology is designed to optimize ion fluxes at the molecular level that will drive the molecular mechanisms leading to cellular asymmetry and cell polarity (CP). ${ }^{1}$ Specific protocols of the REAC technology have been demonstrated to effectively induce direct cell reprogramming ${ }^{2-5}$ and counteract the biological ${ }^{6-9}$ and neurological ${ }^{10-14}$ decay mechanisms linked to aging, such as the degenerative processes of articular cartilage. ${ }^{15}$ In previous studies, REAC technology regenerative tissue optimization (TO-RGN) treatment has decreased nitric oxide and metalloproteinase-3 production in normal and osteoarthritis chondrocytes, while inducing an increase in synthesis of the proteoglycans that are key components of the articular cartilage matrix. ${ }^{15}$ Moreover, REAC technology showed an interesting
Correspondence: Vania Fontani Viale Belfiore 43, 50144 Florence, Italy Tel +39055 290307

Fax +39055290399

Email vfontani@irf.it (c) (i) (-) 2017 Sanna Passino et al. This work is published and licensed by Dove Medical Press Limited. The full terms of this license are available at https://www.dovepress.com/terms.php (c) ${ }_{\mathrm{BY}} \mathrm{NC}$ and incorporate the Creative Commons Attribution - Non Commercial (unported, v3.0) License (http://creativecommons.org/licenses/by-nc/3.0/). By accessing the work you hereby accept the Terms. Non-commercial uses of the work are permitted without any further permission from Dove Medical Press Limited, provided the work is properly attributed. For permission for commercial use of this work, please see paragraphs 4.2 and 5 of our Terms (https://www.dovepress.com/terms.php). 
effect on hyaluronic acid (HA), which plays a fundamental role in $\mathrm{CP}$ and hydrodynamic processes, affording significant modulation of cell proliferation, migration, morphogenesis, and senescence. ${ }^{9}$ Acting on endogenous HA and HA-binding proteins, REAC technology modulates $\mathrm{CP}$ and the intracellular environment. ${ }^{9}$ Hence, REAC technology can modulate endogenous HA synthesis and exert antisenescence actions. ${ }^{9}$ The aging process also affects healing of articular cartilage tissues and is a risk factor for the development of osteoarthritis. Aging reduces the hydration of articular cartilage as well as the mitotic activity and subsequent population size of chondrocytes, which are postmitotic cells more vulnerable to accumulation of aberrant proteins and metabolic waste. The aging-related changes are linked to CP dysregulation with attendant changes in the signaling pathways that control cellular homeostasis, activation, differentiation, and survival. Because REAC TO-RGN treatment has been shown in several studies to affect reparative and regenerative processes, the purpose of the present research was to assess the efficacy of the specific REAC TO-RGN treatment type C in healing experimental chondral lesions in an ovine animal model. The type of lesion studied, if $>3 \mathrm{~mm}$ in diameter, tends to increase in size and depth and does not lead to spontaneous repair with normal hyaline articular cartilage. ${ }^{16}$ However, it leads to chondral defects within the articular cartilage, because the avascular nature of the tissue does not allow for tissue regeneration, filling, or repair. In fact, progenitor cells from the bloodstream or resident chondrocytes in articular cartilage cannot migrate to the lesion, and thus do not contribute to the reparative process. On the contrary, in osteochondral cartilage defects $<3 \mathrm{~mm}$ in diameter, the chondral layer allows access to bone marrow cells, thereby causing vascular damage. The consequent repair response generally begins with a hematoma and results in local production of fibrocartilage tissue that is poorly organized and mechanically inferior compared to the native tissue. ${ }^{17}$ Our hypothesis is that REAC technology, acting by optimizing $\mathrm{CP}$, can induce chondrocyte migration and proliferation to start the reparative and regenerative processes.

\section{Materials and methods}

\section{Ethical considerations}

The animal care and use protocol was in accordance with Italian and European laws on animal treatment in scientific research (Italian Bioethical Committee, Law Decree on the Treatment of Animals in Research, January 27, 1992, No 116). The experimental operations were performed in compliance with established standards for animal welfare and testing
(CIBASA approval by the University of Sassari and the Ministry of Health, protocol N ${ }^{\circ} 25134$ of 10/08/2012).

\section{Experimental design}

This experimental work entailed using four 4-year old female Sardinian sheep, with an average weight of $38 \mathrm{~kg}$. The sheep were clinically free of musculoskeletal diseases and underwent a mini arthrotomy of the articulation of the left and right knees, creating experimental lesions of the medial condyle of each site. The control sheep were left untreated, but only had lesions produced in the left knee (Table 1).

\section{REAC technology}

REAC technology for therapeutic use utilizes asymmetric radioelectric fields to optimize $\mathrm{CP}$ in biological structures, for specific biomodulation effects..$^{2-4,8,15}$ The asymmetric conveyer probe (ACP) is peculiar to this technology, constituting a physical link between the device and the patient's body. The ACP is applied on specific points or areas of the body and makes it possible to create an asymmetric radioelectric circuit in combination with the local electrical environment of the cells or tissues, thus concentrating induced radioelectric microcurrents. The ACP provides an electrical tension reference at the point where it is applied and acts therefore as a pole of attraction. The electrical tension reference is fixed and independent of the applied load (a characteristic of the tissues under treatment). As a result of the asymmetrically conveyed radioelectric microcurrents, the REAC technology is able to normalize existing current flows after their transmission has been altered and reduced quantitatively. The REAC device used in this study was B.E.N.E. (ASMED, Florence, Italy). The REAC treatment utilized in this study is named TO-RGN type C.

TO-RGN includes a set of treatment protocols that are carried out by the ACP applied on specific points or areas of the body.

\section{Surgery}

The anesthesia protocol for all animals consisted of intravenous premedication with fentanyl at $5 \mathrm{mg} / \mathrm{kg}$ (Fentanest $^{\circledR}$

Table I Experimental design

\begin{tabular}{llll}
\hline Period-groups & $\begin{array}{l}\text { Number } \\
\text { of sheep }\end{array}$ & $\begin{array}{l}\text { Stifle joint } \\
\text { (femoral condyle) }\end{array}$ & Treatment \\
\hline 6 months & 2 & Left & REAC RGN type C \\
& & Right & REAC RGN type C \\
6 months & 2 & Left & None \\
Total & 4 & 6 & \\
\hline
\end{tabular}

Abbreviations: REAC, radioelectric asymmetric conveyor; RGN, regenerative treatment. 
$0.1 \mathrm{mg} / 2 \mathrm{~mL}$; Pfizer, New York, NY, USA) and diazepam at $0.3 \mathrm{mg} / \mathrm{kg}$ (Valium ${ }^{\circledR} 10 \mathrm{mg} / 2 \mathrm{~mL}$; Roche, Basel, Switzerland). Epidural anesthesia was administered at the sacral-coccygeal joint while the animal was in a sternal recumbent position, using a $22 \mathrm{~g}$ Quincke spinal needle to inject lidocaine at $2 \mathrm{mg} / \mathrm{kg}$ (Lidocaina ${ }^{\circledR} 2 \%, 20 \mathrm{mg} / \mathrm{mL}$; Pfizer). Beginning 15 minutes after the animals were premedicated, general anesthesia was induced with intravenous lidocaine at $1 \mathrm{mg} / \mathrm{kg}$ (Lidocaina 2\%, $20 \mathrm{mg} / \mathrm{mL}$; Pfizer) and intravenous thiopental at 5-7 mg/kg (Pentothal Sodium ${ }^{\circledR} 1 \mathrm{~g} / 50 \mathrm{~mL}$; MSD Animal Health, New Jersy, USA) followed by intubation of the subject. General anesthesia was then maintained with sevoflurane (Sevo Flo ${ }^{\circledR}$; Abbott, Chicago, IL, USA) of about $1.5 \%$ in $\mathrm{O}_{2}$ at $0.8 \mathrm{~L} / \mathrm{min}$ during mechanical ventilation with volumetric control (Fabius GS; Dräger, Lübeck, Germany) at 12 breaths/min at tidal volumes needed to keep end tidal $\mathrm{CO}_{2}$ at $37-42 \mathrm{mmHg}$ (Infinity Delta; Dräger). During the surgery, $0.9 \% \mathrm{NaCl}$ was infused at $10 \mathrm{~mL} / \mathrm{kg} / \mathrm{h}$. The animals were then placed in dorsal recumbency and arthrotomy of the knee joint was performed to expose the articular surface of the femoral condyles. After thorough disinfection of the skin and preparation of the operative field, the limb was positioned with the knee in full flexion to improve the slip to the bottom of the kneecap. A No 11 scalpel blade was used to perform a full-thickness incision $5 \mathrm{~mm}$ long in the medial side of the tibio-patellar ligament in the convexity of the medial femoral condyle, which was easily palpable transdermally. For the incision, a Gelpi self-retaining retractor was first placed in a distal-proximal location, while a second retractor was positioned perpendicular to the first. This technique exploits the elasticity of the tissues, and by using the Gelpi retractors, it was possible to expose about $1 \mathrm{~cm}^{2}$ of the surface of the femoral condyle (Figure 1A). An osteochondral defect was thus created on the loading area of the medial femoral condyle of the left knee; the field of injury was of a size such as to effectively counter spontaneous healing, ie, it was of the "critical size" as suggested in the literature. For sheep, this critical size entails a cylindrical shape with a $6 \mathrm{~mm}$ diameter and a $2 \mathrm{~mm}$ depth, with sharp margins and localization to the femoral condyle. To standardize these lesions, a punch with diameter of $6 \mathrm{~mm}$, normally used for osteochondral transplantations, was used. It rested on the joint surface and was gently rotated clockwise and counterclockwise, delimiting the borders of the surgical defect (Figure 1B). The articular cartilage tissue within the area of the lesion was removed by milling with the cylindrical tip and finished with a curette applied to the surface of the bone to a depth of about $2 \mathrm{~mm}$ (Figure 1C-E). Continuous irrigation with $0.9 \% \mathrm{NaCl}$ was maintained throughout the surgery to avoid heating the articular cartilage in the area where the milling cutter was used or drying the articular surface by exposure to the room air. Then, reconstruction was performed "lege artis" using sutures in separate planes of the joint capsule and the skin with synthetic absorbable monofilament (Monocryl U.S.P. 4/0) (Figure 1F and G).

\section{Postoperative treatment}

All subjects were housed postoperatively in small enclosures and treated with the $24 \mathrm{~h}$ REAC TO-RGN protocol for 7 consecutive days. The ACP probe was applied to both legs in the hip femoral-tibial-patellar region and was replaced every $12 \mathrm{~h}$. After treatment, the animals were confined in small spaces so as to limit movement and then returned to pasture until euthanasia was performed at 6 months to complete the study. After surgery, all subjects were clinically evaluated daily during the first week of REAC TO-RGN treatment (Figure 2A and B); following the removal of cutaneous suture points, the clinical evaluation
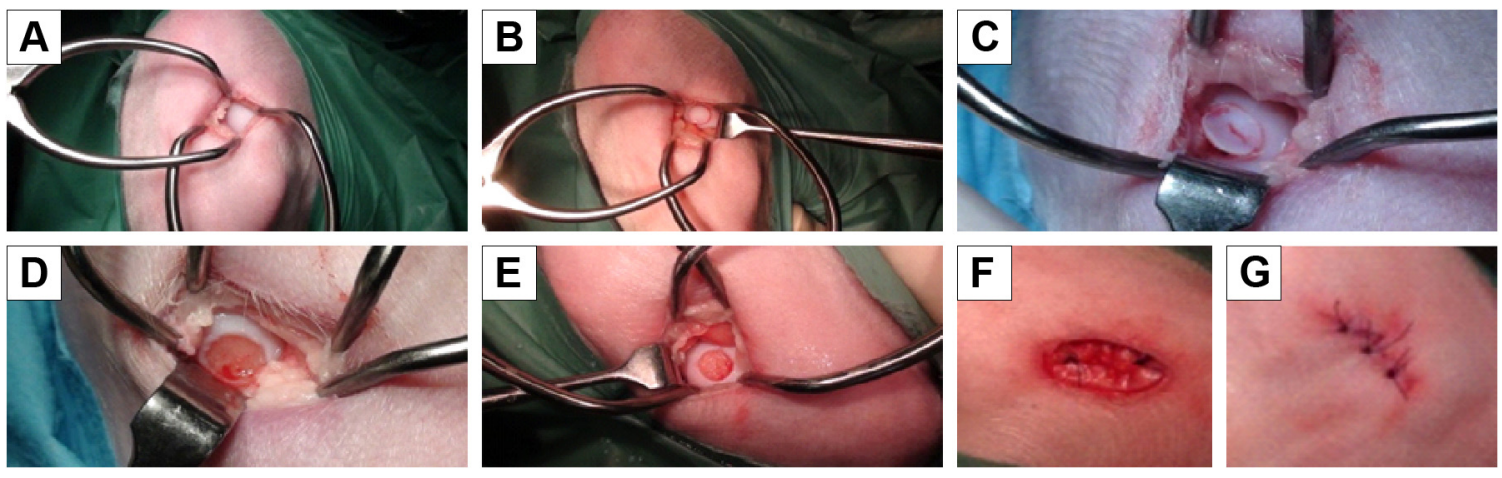

Figure I Surgical phases.

Note: Surgical phases: (A) mini arthrotomy, (B) double gelpi self-retaining retractor placement, (C-E) osteochondral defect (6 mm diameter and a 2-mm depth, with sharp margins and localization to the femoral condyle), (F) (G) reconstruction (performed "lege artis" with the suture in separate planes of the joint capsule and the skin with synthetic absorbable monofilament Monocryl U.S.P 4/0). 

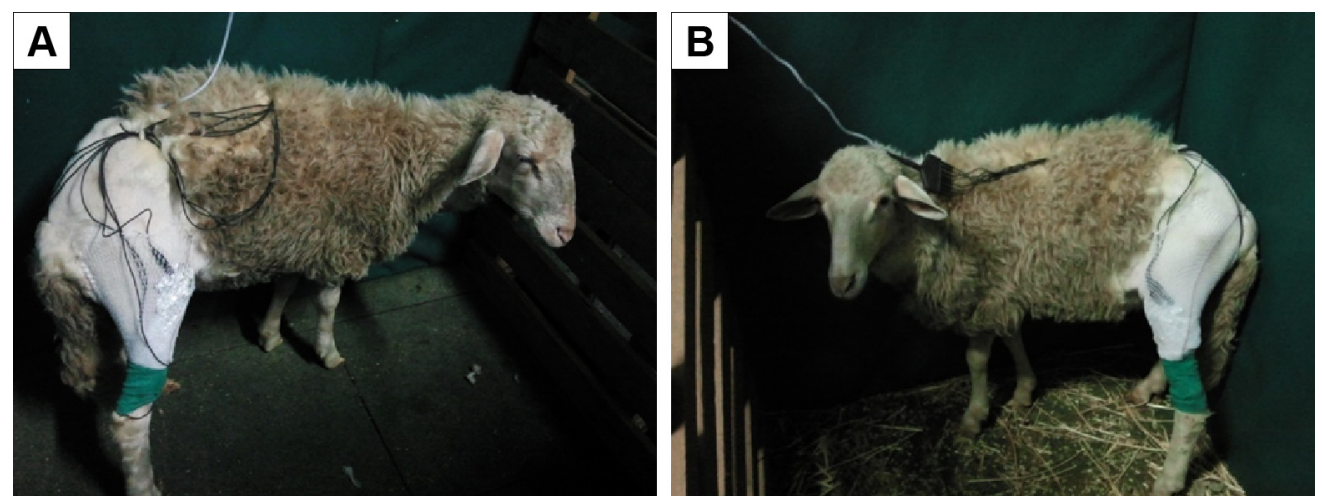

Figure 2 REAC TO-RGN treatment (A) right leg, (B) left leg.

Abbreviations: REAC, radioelectric asymmetric conveyor; REAC TO-RGN, REAC technology regenerative tissue optimization.

of the animals took place once a week until euthanasia. All samples were subjected to macroscopic, histological, and immunohistochemical evaluation of the ultrastructure of the regenerated tissues and also assesses for their integration with the surrounding tissue.

\section{Macroscopic assessment}

As mentioned in the "Postoperative treatment" section, the sheep were euthanized 6 months after treatment and both femoral condyles were exposed and transversely sectioned perpendicular to the articular surface about $1-2 \mathrm{~cm}$ deep to evaluate the quality of the newly formed tissue, and the changes were documented photographically. The regenerating tissue in the articular cartilage defects was also examined by two observers who both applied the semiquantitative scoring system developed by the International Articular cartilage Repair Society and modified by the authors (Table S1). ${ }^{19}$ The resulting values were averaged. Observations were initially recorded as percentages (surface appearance, filling of the defect, and graft-host integration at the margins).

\section{Histological and immunohistochemistry procedures}

Condylar articular defects were removed as osteochondral blocks (thickness: $0.5 \mathrm{~cm}$; width: $2-3 \mathrm{~cm}$; height: 1-2 cm; distance of cutting from edges of defect: $0.5 \mathrm{~cm}$ ) by using a circular saw with water cooling of the blade to avoid overheating. It was important to evaluate the defect in all of its aspects, and therefore each defect was sectioned into two parts (A and B) and each part was scored (Figure 3). The blocks were fixed in 10\% neutral-buffered formalin for 2-4 days and were then transferred to a volume of a decalcification solution (1:1 acid citric/formic acid solution) about 20 times the volume of the samples and then placed on a magnetic stirrer for 2-4 days. Then, after washing the tissues in running tap water for 4-8 $\mathrm{h}$ to remove all traces of the decalcification solution, the samples were dehydrated as follows: alcohol $50 \%$ for an indefinite time (standby step); alcohol $80 \%$ for $4 \mathrm{~h}$ at $40^{\circ} \mathrm{C}$; alcohol $90 \%$ for $4 \mathrm{~h}$ at $40^{\circ} \mathrm{C}$; alcohol $100 \%$ for $4 \mathrm{~h}$ at $40^{\circ} \mathrm{C} ; 3$ steps in xylene of $1 \mathrm{~h}$ each at $40^{\circ} \mathrm{C}$; and finally 3 steps for paraffin infiltration of $45 \mathrm{~min}$ each at $59^{\circ} \mathrm{C}$. After embedding the tissue blocks in paraffin wax, they were mounted on a microtome and oriented to provide $3-\mu \mathrm{m}$ sagittal sections of

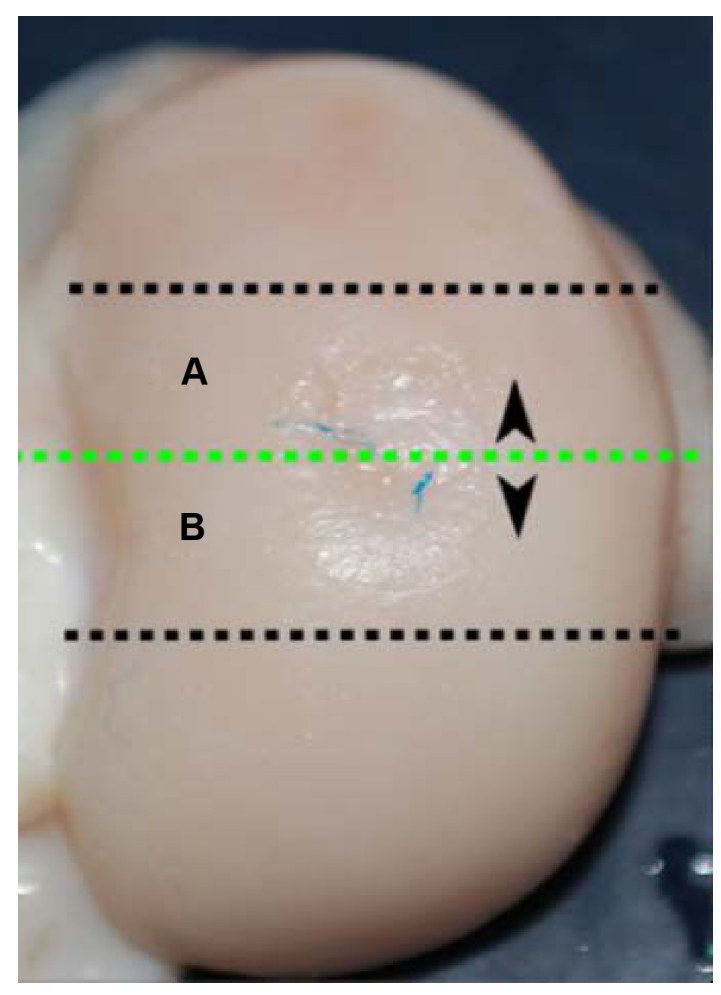

Figure 3 Preparation of the condyles.

Notes: Trimming of lesion; line section of lesion $(\mathbf{A})$ and $(\mathbf{B})$ half lesion. 
the surgical defect. Slices were mounted on 3-aminopropyltriethoxylane-pretreated slides to avoid detachment. To evaluate general tissue morphology, sections were stained with hematoxylin and eosin to evaluate the matrix articular cartilage composition; azan-Mallory staining to assess the presence, amount, and distribution of the collagen fibers; and Safranine-O stain to reveal the distribution of proteoglycans. All slides were processed together to prevent variations of histological processing.

To analyze the expression of type II collagen in the articular cartilage, the histological sections were deparaffinized, rehydrated, and incubated at $37^{\circ} \mathrm{C}$ with proteinase $\mathrm{K}$ to unmask the antigen binding sites. The endogenous peroxidases were blocked by 30 min of incubation in Dako REAL Peroxidase-Blocking Solution (S2023; Dako, Glostrup, Denmark), and the saturation of nonspecific binding sites was obtained using 2.5\% normal horse serum (ImmPRESS reagent kit; Vector Labs, Burlingame, CA, USA) for $30 \mathrm{~min}$ at room temperature. Then, sections were incubated overnight at $4{ }^{\circ} \mathrm{C}$ with a type II collagen rabbit polyclonal antibody (anti-collagen type II LS-C18868 LSBio) at a 1:20.000 dilution. After about $16 \mathrm{~h}$ at $4^{\circ} \mathrm{C}$, the sections were incubated for $30 \mathrm{~min}$ at room temperature with anti-mouse/ rabbit secondary antibody peroxidase conjugate (MP-7500, ImmPRESS reagent kit Peroxidase; Vector Labs). After staining with 3,3'-diaminobenzidine (ImmPACT DAB; Vector Labs), tissues were counterstained with hematoxylin, cover-slipped with Eukitt Mounting MediumTM (BiOptica, Milan, Italy), and observed under light microscopy. The femoral condyle obtained from the untreated sheep served as positive control. Negative controls were those in which primary antibody was omitted. Lesions were recorded using a Nikon Ds-fil digital camera.

\section{Evaluation of histological and immunohistochemical data}

The histological regeneration was evaluated independently by two observers using an articular cartilage repair grading system derived from Caplan et al, ${ }^{18}$ and Pilichi et al ${ }^{19}$ and modified by the authors' (Table S2). The two values obtained for each sample were averaged.

\section{Results}

\section{Treated group - Evaluation 6 months after REAC TO-RGN treatment}

The macroscopic analysis after 6 months showed a similarity in the regeneration process of the two right and left condyles. The lesion appeared filled, though not completely, with newly generated tissue of the light opalescent color similar to that of healthy articular cartilage, which covered the underlying subchondral bone completely (Figure 4A, F, K, and P). The newly formed tissue surface appeared to be quite regular, and the continuity with the healthy tissue appeared to be good, an index of acceptable integration with the margins of the lesion. No breakages or cracks in the newly formed tissue were seen. The macroscopic results for the two subjects showed scores of $20.75 / 24$ and $16.25 / 24$ points, with a mean value of $18.5 / 24$ points (Table 1 ). The macroscopic observations were confirmed by histological examinations. In fact, after 6 months the subjects reached overall scores of 37.75/62 and 48/62 with a mean of $42.87 / 62$ points (Table 2 ).

Histologically, the formation of immature hyaline articular cartilage covering the lesion in a uniform manner but with some slight irregularities and deformations of the surface was documented. Furthermore, the filling was not complete, consistent with the macroscopic observations.

Table 2 Macroscopical score

\begin{tabular}{|c|c|c|c|c|c|c|c|c|c|c|c|c|c|}
\hline \multirow[t]{2}{*}{ Sheep } & \multirow[t]{2}{*}{ Condyle } & \multirow{2}{*}{$\begin{array}{l}\text { Half } \\
\text { lesion }\end{array}$} & \multicolumn{3}{|c|}{ Surface } & \multicolumn{5}{|c|}{ Section aspect } & \multirow[t]{2}{*}{ Total } & \multirow{2}{*}{$\begin{array}{l}\text { Mean half } \\
\text { lesions }\end{array}$} & \multirow{2}{*}{$\begin{array}{l}\text { Mean } \\
\text { subject }\end{array}$} \\
\hline & & & $\%$ Fd & SI & $\overline{\text { S2 }}$ & Grti & Sct I & Sct2 & Sct3 & Sct4 & & & \\
\hline 6 months & Left medial & $A$ & 2 & 3 & 4 & 2 & 3 & 2 & 3 & 3 & 22 & 21 & 20,75 \\
\hline \multirow[t]{3}{*}{ treated } & condyle & B & 2 & 3 & 4 & 2 & 2 & I & 3 & 3 & 20 & & \\
\hline & Right medial & $\mathrm{A}$ & 2 & 3 & 3 & 3 & 2 & 2 & 3 & 3 & 21 & 20,5 & \\
\hline & condyle & B & 2 & 3 & 3 & 3 & I & 2 & 3 & 3 & 20 & & \\
\hline 6 months & Left medial & $A$ & 2 & 2 & 3 & I & I & I & 3 & 3 & 16 & 16 & 16,25 \\
\hline \multirow[t]{3}{*}{ treated } & condyle & B & 2 & 2 & 3 & I & I & I & 3 & 3 & 16 & & \\
\hline & Right medial & $A$ & 2 & 2 & 2 & I & I & 1 & 3 & 3 & 15 & 16,5 & \\
\hline & condyle & B & 2 & 2 & 2 & 2 & 2 & 2 & 3 & 3 & 18 & & \\
\hline 6 months & Left medial & A & 0 & I & 0 & 0 & 0 & I & 3 & 3 & 8 & & 8 \\
\hline untreated & condyle & B & 0 & I & 0 & 0 & 0 & I & 3 & 3 & 8 & & \\
\hline 6 months & Left medial & $\mathrm{A}$ & I & $\mathrm{I}$ & I & I & 3 & 2 & 3 & I & 13 & & 13 \\
\hline untreated & condyle & B & I & I & I & I & 3 & 2 & 3 & I & 13 & & \\
\hline
\end{tabular}

Abbreviations: \% Fd, percent area of defect filled; SI, tissue aspect; S2, regularity; Grti, graft-recipient tissue integration; Sct I, depth; Sct2, tissue aspect; Sct3, subchondral cysts; Sct4, periarticular remodeling. 


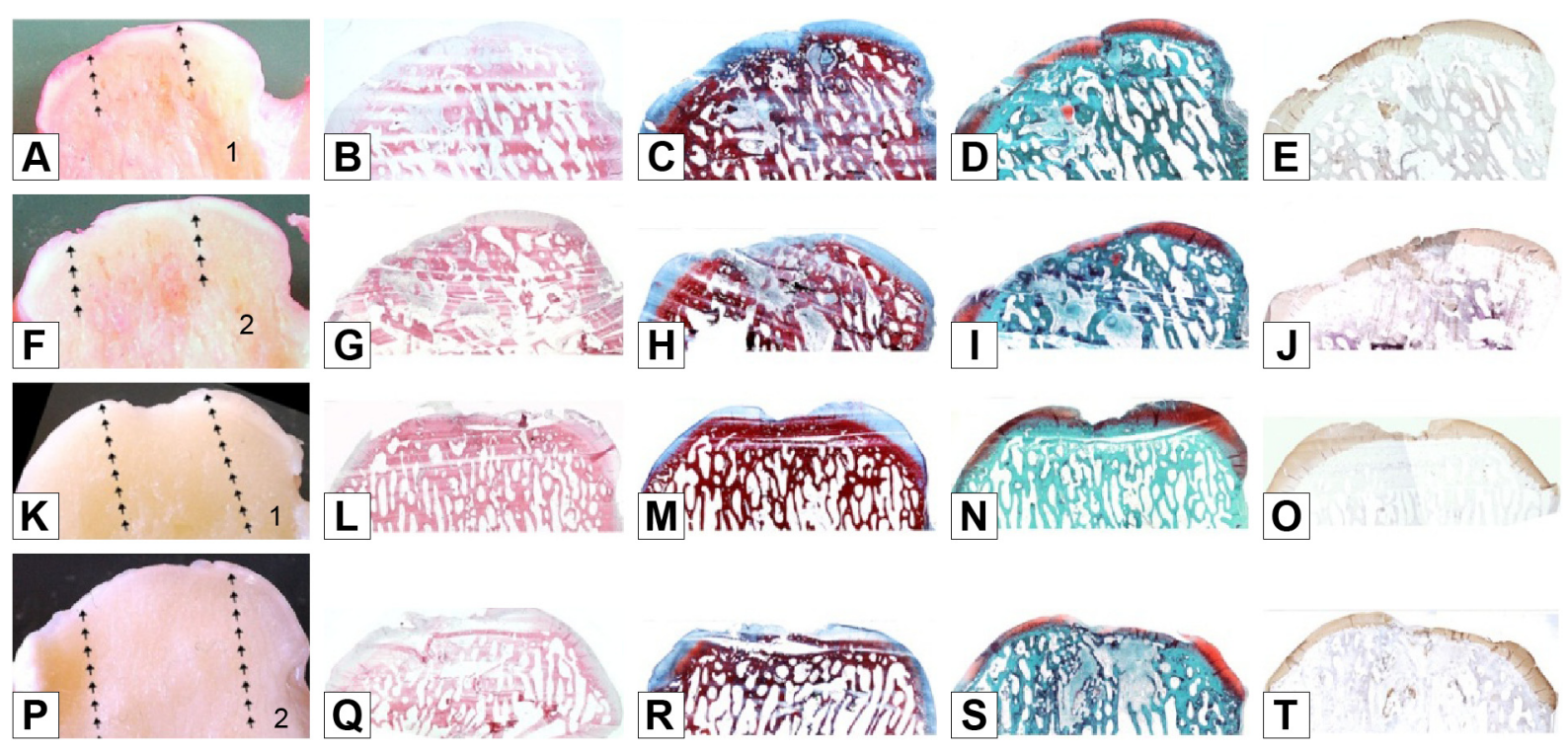

Figure $\mathbf{4}$ Treated group: macro and histological observations of 2 condyles, sectioned in half (number I in images $\mathbf{A}$ and $\mathbf{K}$ : right hemicondyle; number 2 in images $\mathbf{F}$ and P: left hemicondyle).

Notes: Macroscopic appearance: A, F, K, P. Histological appearance: B, G, L, Q haematoxylin and eosin staining; C, H, M, R azan-mallory staining; D, I, N, S safranine-O staining; E, J, $\mathbf{O}, \mathbf{T}$ type II collagen immunostaining. Magnification $\times 20$.

Actually, we did not observe significant differences between the articular cartilage harvested from the two sheep, as is revealed by these scores. The structure of the newly formed tissue has the characteristics of immature hyaline articular cartilage, with numerous isogenic proliferation groups both in the margins and in the center of the lesion as well as many active chondroblasts and chondrocytes. The integration with the bone looked good, and there were observable beginnings of ossification of the deep articular cartilage, and sketchy tidemarks (the junction between calcified and uncalcified cartilage) albeit intermittently. The subchondral bone showed signs of remodeling and ossification. There were no cavities or subchondral cysts. The specific coloration of the proteoglycan matrix deposition appeared good, as did the coloration of collagen II markings which were quite similar to that of the healthy articular cartilage in both the left and right condyle. The most interesting observations were seen with respect to bone morphology repairs. Here we observed nearly complete regeneration of subchondral bone in final structure, with little vascularization and with the ossification nuclei almost absent (Figure 4). This finding was confirmed by the bone score that showed a gap of $29 \%$ between the treated and untreated subjects ( $6.88 / 9$ vs $4.25 / 9$ points, based on the mean value from all the samples). Furthermore, the morphologic findings showed a gap of $35.22 \%$ between the treated and untreated subjects ( $7.88 / 9$ vs $4 / 9$ points, based on the mean of all samples). In all of the observed samples, the tidemarks appeared irregular and incomplete, and the marking of the matrix was good, as we had already observed in the untreated samples. The mean of total score of the repair process of macro- and micro-REAC TO-RGN type C-treated subjects was $61.37 / 86$ and $71.37 \%$, respectively (Tables 1-3).

\section{Untreated group evaluation after 6 months}

The untreated subjects' condyles showed a considerably delayed reparative process after 6 months compared to the subjects treated with REAC TO-RGN. Macroscopically, the lesions were filled incompletely and had irregular surface characteristics. In all the untreated condyles, a poor repair with large depressed areas covered by fibrous tissue occurred. In particular, the left condyles had a deep cavity that penetrated into the subchondral bone (Figure 5A, F, K, and P). The presence of the cavities was confirmed histologically. In the left condyle, a fibrous tissue cover was found, with few chondrogenic elements. One condyle appeared to have obvious cysts (Figure 5H and $\mathrm{M}$ ). The matrix of the condyles showed a little staining and an evident absence of collagen II, in large part demonstrating a lack of articular cartilage formation. Moreover, the matrix deposition was not uniform and articular cartilage islands were immersed in fibrous tissue, which had detectable appearances without uniform indications of collagen II staining (Figure 5E, J, O, and T). The extent of the bone remodeling was still sizeable, a sign that ossification had not yet happened. No development of tidemarks was observed 
Table 3 Microscopical score

\begin{tabular}{|c|c|c|c|c|c|c|c|c|c|c|c|c|}
\hline Sheep & Cond & $\begin{array}{l}\text { Half } \\
\text { lesion }\end{array}$ & Cart $^{\mathrm{a}}$ & Bone $^{b}$ & Morph' & Vasc $^{d}$ & $\operatorname{Deg}^{\mathrm{e}}$ & Infl & Matrf & Tot & $\begin{array}{l}\text { Mean half } \\
\text { lesions }\end{array}$ & $\begin{array}{l}\text { Mean } \\
\text { subject }\end{array}$ \\
\hline 6 months & Left medial & $\mathrm{A}$ & 2 & 4 & 6 & 0 & 8 & 3 & 5 & 28 & 32 & 37,75 \\
\hline \multirow[t]{3}{*}{ treated } & condyle & B & 7 & 6 & 8 & 0 & 9 & 3 & 3 & 36 & & \\
\hline & Right medial & $\mathrm{A}$ & 7 & 6 & 9 & 1 & 10 & 3 & 4 & 40 & 43,5 & \\
\hline & condyle & $B$ & 7 & 6 & 8 & 4 & 12 & 3 & 7 & 47 & & \\
\hline 6 months & Left medial & A & 6 & 9 & 8 & 4 & 10 & 3 & 7 & 47 & 45,5 & 48 \\
\hline \multirow[t]{3}{*}{ treated } & condyle & B & 6 & 7 & 8 & 3 & 10 & 3 & 7 & 44 & & \\
\hline & Right medial & A & 7 & 9 & 9 & 7 & II & 3 & 7 & 53 & 50,5 & \\
\hline & condyle & $B$ & 7 & 8 & 7 & 7 & 9 & 3 & 7 & 48 & & \\
\hline 6 months & Left medial & $A$ & 5 & 4 & 6 & 0 & 12 & 3 & 4 & 34 & & 28,5 \\
\hline untreated & condyle & $B$ & 2 & I & 5 & 0 & 8 & 3 & 4 & 23 & & \\
\hline 6 months & Left medial & A & 6 & 6 & 2 & 3 & 11 & 0 & 4 & 32 & & 32,5 \\
\hline untreated & condyle & B & 6 & 6 & 3 & 3 & II & 0 & 4 & 33 & & \\
\hline
\end{tabular}

Notes: ${ }^{\mathrm{C}} \mathrm{Cl}+\mathrm{C} 2+\mathrm{C} 3$; ${ }^{\mathrm{b}} \mathrm{BI}+\mathrm{B} 2$; ${ }^{\mathrm{c}} \mathrm{Fd}+\mathrm{Edg}+\mathrm{Int}+\mathrm{Tdk}$; ${ }^{\mathrm{V}} \mathrm{I}+\mathrm{V} 2$; ${ }^{\mathrm{e}} \mathrm{DI}+\mathrm{D} 2+\mathrm{D} 3+\mathrm{D} 4{ }^{\mathrm{i}} \mathrm{MI}+\mathrm{M} 2+\mathrm{M} 3$.

Abbreviations: Cart, cartilage; Cond, condyle; Deg, degeneration; Matr, matrix staining; Morph, morphology; Tot, total; Vasc, vascular; $\mathrm{Cl}$, surface regularity; C2, cell type; C3, tissue type; BI, ossification; B2, cell type; Fd, filling of defect; Edg, edges of defect; Int, integration between cartilage and bone plate; Tdk, tidemark, VI amount; V2, distribution; DI, degree of articular deterioration; D2, subchondral bone sclerosis; D3, periarticular remodeling or lipping; D4, subchondral bone cysts; Inf, inflammation; Ms I, collagen staining with Azan-Mallory; Ms2, proteoglycan staining with Safranine-O; Ms3, collagen type II immunostaining.

in any of the condyles. The mean total score of macro- and micro-ossification of the untreated subjects was $41 / 86$, with $47.67 \%$ of the repair process evident (Tables $1-3$ ).

\section{Discussion}

The regeneration of articular cartilage represents an important challenge, and so numerous approaches have been proposed to promote the repair process. Clinical treatment strategies like mosaicplasty, autologous chondrocyte injection, and microfractures have produced unsatisfactory long-term results. ${ }^{20}$ In recent years, the availability of tissue engineered products has led to proposals for different biological substitutes to restore or improve functionality of damaged tissues. Biomaterial scaffolds can play a critical role by providing a 3-dimensional environment to support cell growth, matrix deposition, and tissue regeneration. Although biomaterials can provide excellent physiochemical properties that play a key role in guiding articular cartilage tissue regeneration

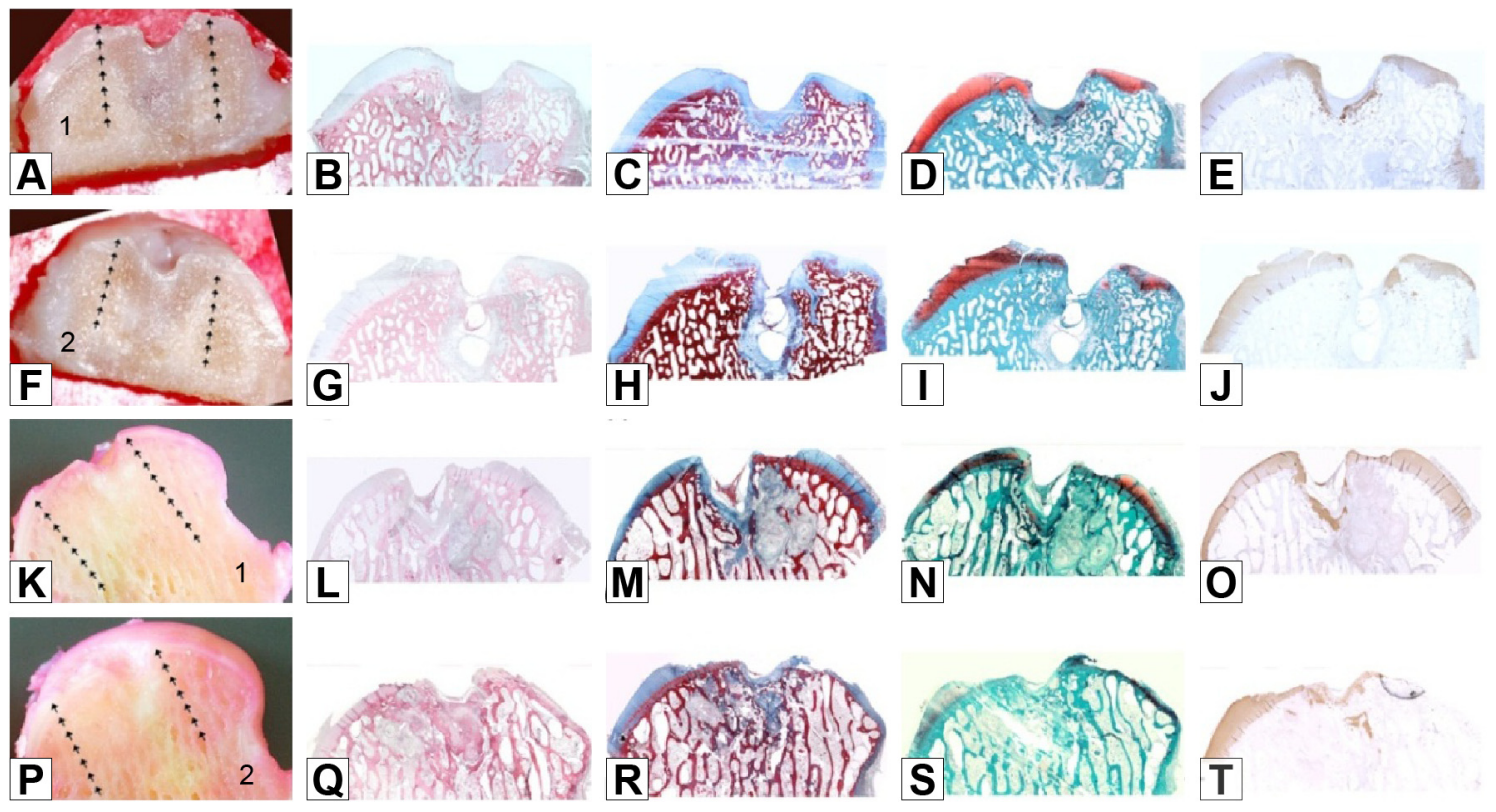

Figure $\mathbf{5}$ Untreated group: macro and histological observations of 2 condyles, sectioned in half (number I in images $\mathbf{A}$ and $\mathbf{K}$ : right hemicondyle; number 2 in images $\mathbf{F}$ and $\mathbf{P}$ : left hemicondyle).

Notes: Macroscopic appearance: A, F, K, P. Histological appearance: B, G, L, Q haematoxylin and eosin staining; C, H, M, R azan-mallory staining; D, I, N, S safranine-O staining; E, J, O, T type II collagen immunostaining. Magnification $\times 20$. 
in vitro, deterioration of articular cartilage regenerated at defect sites in vivo occurs frequently. ${ }^{21}$

For the past several years, the use and efficacy of physical treatments has been investigated for chondral pathologies. REAC technology treatments are one of these candidate strategies and have opened new therapeutic perspectives for reparative and regenerative orthopedic processes. REAC technology has previously shown that somatic cells can be directly reprogrammed to differentiate into alternative forms without first going through transformation back to stem/progenitor cells. In human skin fibroblasts, the REAC technology induced remarkable commitments to cardiac, neuronal, or skeletal muscle lineages. This included transcription of tissue-restricted genes, including Mef2c, Tbx5, GATA4, $N k x 2.5$, and prodynorphin for cardiac reprogramming, as well as $m y o D$ and neurogenin 1 for skeletal myogenesis and neurogenesis, respectively. Conversely, REAC treatment elicited a biphasic effect on a number of stemness-related genes, leading to early transcriptional increase of Oct4, Sox 2, cMyc, Nanog, and Klf4 within 6-20 h of treatment, followed by a downregulation at later times. The REAC action bypassed persistent reprogramming and induced a pluripotent stem cell-like state that involved the transcriptional induction of the NADPH oxidase subunit Nox4.

The REAC technology mechanism of action is based on $\mathrm{CP}$ optimization. ${ }^{9,22} \mathrm{CP}$ is a universal biological phenomenon that has been implicated in cell differentiation, proliferation, and morphogenesis. The establishment and maintenance of correct CP is crucial for normal cell physiology and tissue homeostasis of chondrocytes as well. ${ }^{23,24}$

This work was designed to investigate REAC TO-RGN type $\mathrm{C}$ timing and an administration protocol to treat agingrelated damage and injuries caused by trauma in order to help elucidate regenerative processes occurring in articular cartilage for human medicine in a model where the zone of injury is of a size sufficient to effectively inhibit spontaneous healing. The choice of the sheep model was suggested by its extensive use previously for study of regenerative processes in articular cartilage tissue. ${ }^{25-27}$ The choice to use only four animals, two treated and two controls, was made to minimize unnecessary harm, given that this was a preliminary study designed to gain information for the timing and administration of the TO-RGN type C. The duration of the protocol was limited to 6 months, the minimum time needed to evaluate an initial lesion repair.

\section{Conclusion}

The results obtained in this preliminary study seem encouraging, both in terms of quantity and quality. In fact, the comparison of the scores obtained between the treated and untreated groups shows a positive score in favor of the REAC TO-RGN type C-treated group. The present work shows the efficacy of REAC TO-RGN type $\mathrm{C}$ as a therapeutic tool, among the other REAC RGN protocols, in the treatment of articular cartilage damages, although future investigations are needed.

\section{Acknowledgments}

This work was funded by Fondazione di Sardegna (3320/2013), Regione Autonoma della Sardegna, Fundamental Research Program, L.R. 7/2007 "Promotion of the scientific research and technological innovation in Sardinia" (CRP 60208) and by the Rinaldi Fontani Foundation, Florence, Italy.

\section{Author contribution}

ESP collaborated in conceiving the experimental design and writing the manuscript; SR and VF invented REAC technology, collaborated in conceiving the experimental design, and aided in writing the manuscript; Stefano Rocca performed histological analyses; AC collaborated in conceiving the experimental design; SC and NC collaborated in performing the experiments; all authors read and approved the final manuscript. All authors contributed toward data analysis, drafting and critically revising the paper and agree to be accountable for all aspects of the work.

\section{Disclosure}

SR and VF are the inventors of the radioelectric asymmetric conveyer technology. The authors report no other conflicts of interest in this work.

\section{References}

1. Campanale JP, Sun TY, Montell DJ. Development and dynamics of cell polarity at a glance. J Cell Sci. 2017;130(7):1201-1207.

2. Maioli M, Rinaldi S, Santaniello S, et al. Radiofrequency energy loop primes cardiac, neuronal, and skeletal muscle differentiation in mouse embryonic stem cells: a new tool for improving tissue regeneration. Cell Transplant. 2012;21(6):1225-1233.

3. Maioli M, Rinaldi S, Santaniello S, et al. Radio electric conveyed fields directly reprogram human dermal skin fibroblasts toward cardiac, neuronal, and skeletal muscle-like lineages. Cell Transplant. 2013; 22(7):1227-1235.

4. Maioli M, Rinaldi S, Santaniello S, et al. Radioelectric asymmetric conveyed fields and human adipose-derived stem cells obtained with a nonenzymatic method and device: a novel approach to multipotency. Cell Transplant. 2014;23(12):1489-1500.

5. Maioli M, Rinaldi S, Migheli R, et al. Neurological morphofunctional differentiation induced by REAC technology in PC12. A neuro protective model for Parkinson's disease. Sci Rep. 2015;5:10439.

6. Rinaldi S, Maioli M, Santaniello S, et al. Regenerative treatment using a radioelectric asymmetric conveyor as a novel tool in antiaging medicine: an in vitro beta-galactosidase study. Clin Interv Aging. 2012; 7:191-194.

7. Maioli M, Rinaldi S, Santaniello S, et al. Anti-senescence efficacy of radio-electric asymmetric conveyer technology. Age. 2014;36(1): 9-20. 
8. Rinaldi S, Maioli M, Pigliaru G, et al. Stem cell senescence. Effects of REAC technology on telomerase-independent and telomerasedependent pathways. Sci Rep. 2014;4:6373.

9. Maioli M, Rinaldi S, Pigliaru G, et al. REAC technology and hyaluron synthase 2, an interesting network to slow down stem cell senescence. Sci Rep. 2016;6:28682.

10. Rinaldi S, Mura M, Castagna A, Fontani V. Long-lasting changes in brain activation induced by a single REAC technology pulse in Wi-Fi bands. Randomized double-blind fMRI qualitative study. Sci Rep. 2014;4:5668.

11. Panaro MA, Carofiglio V, Calvello R, et al. Modulation of proinflammatory response in a mouse model of Parkinson's disease by noninvasive physical approach. Paper presented at: Microwave Symposium (MMS), 2015 IEEE 15th Mediterranean; November 30, 2015-December 2, 2015.

12. Rinaldi S, Calza L, Giardino L, Biella GE, Zippo AG, Fontani V. Radio electric asymmetric conveyer: a novel neuromodulation technology in Alzheimer's and other neurodegenerative diseases. Front Psychiatry. 2015;6:22.

13. Zippo AG, Rinaldi S, Pellegata G, et al. Electrophysiological effects of noninvasive Radio Electric Asymmetric Conveyor (REAC) on thalamocortical neural activities and perturbed experimental conditions. Sci Rep. 2015;5:18200.

14. Luca L, Alessandro G, Sandra S, et al. REAC technology modifies pathological neuroinflammation and motor behavior in an Alzheimer's disease mouse model. Sci Rep. 2016;6:35719.

15. Collodel G, Fioravanti A, Pascarelli NA, et al. Effects of regenerative radioelectric asymmetric conveyer treatment on human normal and osteoarthritic chondrocytes exposed to IL-1beta. A biochemical and morphological study. Clin Interv Aging. 2013;8:309-316.

16. Buckwalter J, Rosenberg LC, Hunziker EB. Articular cartilage: composition, structure, response to injury, and methods to facilitating repair. In: Whit E, editor. Articular Cartilage and Knee Joint Function. Basic Science and Arthroscopy. New York, NY: Raven Press; 1990:19-56.
17. Steinert AF, Ghivizzani SC, Rethwilm A, Tuan RS, Evans CH, Noth U. Major biological obstacles for persistent cell-based regeneration of articular cartilage. Arthritis Res Ther. 2007;9(3):213.

18. Caplan AI, Elyaderani M, Mochizuki Y, Wakitani S, Goldberg VM. Principles of cartilage repair and regeneration. Clin Orthop Relat Res. 1997;342:254-269.

19. Pilichi S, Rocca S, Pool RR, et al. Treatment with embryonic stem-like cells into osteochondral defects in sheep femoral condyles. BMC Veter Res. 2014;10:301.

20. Kock L, van Donkelaar CC, Ito K. Tissue engineering of functional articular cartilage: the current status. Cell Tissue Res. 2012;347(3): 613-627.

21. Zhang $\mathrm{L}, \mathrm{Hu} \mathrm{J}$, Athanasiou KA. The role of tissue engineering in articular cartilage repair and regeneration. Critic Rev Biomed Eng. 2009; $37(1-2): 1-57$

22. Berlinguer F, Pasciu V, Succu S, et al. REAC technology as optimizer of stallion spermatozoa liquid storage. Reprod Biol Endocrinol. 2017; 15(1):11.

23. Gao B, Yang Y. Planar cell polarity in vertebrate limb morphogenesis. Curr Opin Genet Dev. 2013;23(4):438-444.

24. Kuss P, Kraft K, Stumm J, et al. Regulation of cell polarity in the cartilage growth plate and perichondrium of metacarpal elements by HOXD13 and WNT5A. Dev Biol. 2014;385(1):83-93.

25. Jelic M, Pecina M, Haspl M, et al. Regeneration of articular cartilage chondral defects by osteogenic protein-1 (bone morphogenetic protein-7) in sheep. Growth Factor. 2001;19(2):101-113.

26. Jubel A, Andermahr J, Schiffer G, et al. Transplantation of De Novo Scaffold-free cartilage implants into sheep knee chondral defects. Am J Sports Med. 2008;36(8):1555-1564.

27. Kon E, Filardo G, Delcogliano M, et al. Platelet autologous growth factors decrease the osteochondral regeneration capability of a collagenhydroxyapatite scaffold in a sheep model. BMC Musculoskel Dis. 2010;11:220.
Clinical Interventions in Aging

\section{Publish your work in this journal}

Clinical Interventions in Aging is an international, peer-reviewed journal focusing on evidence-based reports on the value or lack thereof of treatments intended to prevent or delay the onset of maladaptive correlates of aging in human beings. This journal is indexed on PubMed Central, MedLine,

\section{Dovepress}

CAS, Scopus and the Elsevier Bibliographic databases. The manuscript management system is completely online and includes a very quick and fair peer-review system, which is all easy to use. Visit http://www.dovepress. com/testimonials.php to read real quotes from published authors. 